\title{
Cognitive effects of dopaminergic and glutamatergic blockade in nucleus accumbens in pigeons
}

\author{
P.A. Gargiulo ${ }^{\text {a,* }}$, M.J. Acerbo ${ }^{\text {b,1 }}$, I. Krug ${ }^{\text {b }}$, J.D. Delius ${ }^{\text {b }}$ \\ ${ }^{a}$ Laboratorio de Neurociencias y Psicología Experimental (IMBECU-CONICET), Dept. Patologia, F.C.M., U. N. de Cuyo, \\ y Universidad Católica Argentina, Mendoza (5500), Argentina \\ 'Allgemeine Psychologie, Universität Konstanz, 78434 Konstanz, Germany'
}

\begin{abstract}
In earlier studies it was found that glutamatergic transmission within the nucleus accumbens septi is involved in the performance of a learned visual shape discrimination in pigeons. This study examines what effects several kinds of glutamate and dopamine antagonists have on the same task. Pigeons were trained with the relevant discrimination, bilaterally implanted with cannulas into the nucleus accumbens and tested after various transmission blockers had been administered intracerebrally. SCH-23390, a D1 dopamine antagonist, at the dose used, had no effect, and Spiperone, a D2-dopamine and 5HT2a-serotonine antagonist, significantly decreased the error repeat trials. CNQX, a nonNMDA glutamate receptor antagonist, and Cycloleucine, an antagonist of the glycine allosteric site of NMDA receptors, had no effect. CGS19755, a selective competitive NMDA antagonist, significantly impaired performance by significantly decreasing the percent correct trials and increasing the error repeat trials. CPPG, a II/III metabotropic glutamate antagonist, remarkably improved performance. MMPG, a III/II metabotropic glutamate antagonist, at the dose used, did not have any significant effect. The preparation employed may be a useful animal model of perceptual disturbances in schizophrenia.
\end{abstract}

Keywords: Pigeon; Nucleus accumbens; Perception; Learned discrimination; Glutamate antagonists; Dopamine antagonists; Schizophrenia

The basal forebrain accumbens septi nucleus (Acc) has received considerable attention in recent years because of its probable involvement in the pathophysiology of schizophrenia (Gray, 1995; Heimer, 2000). In mammals, the nucleus is a major component of the ventral striatum and receives among other inputs dopaminergic projections from the ventro-tegmental area and glutamatergic projections from the cortico-limbic system. In the past it has been considered to be mainly concerned with motor, stereotypy and reward functions (Baldo et al., 2002; Gargiulo, 1996; Kelley and Berridge, 2002). More recently the Acc has been also connected with anxiety control and cognitive process-

\footnotetext{
* Corresponding author. Laboratorio de Neurociencias y Psicología Experimental, Casilla de Correo 7, Mendoza 5500, Argentina.

E-mail address: gargiulo@lab.cricyt.edu.ar (P.A. Gargiulo).

1 Present address: M.J.A., Biopsychology Program, Psychology Department, University of Michigan, USA.
}

ing (Di Ciano et al., 2001; Gargiulo et al., 1999; Martinez et al., 2002a,b; Roullet et al., 2001). Both dopaminergic and glutamatergic mechanisms seem to intervene in several of these Acc functions (Aultman and Moghaddam, 2001; Baldwin et al., 2002; Smith-Roe and Kelley, 2000).

Comparative studies indicate that an Acc is present in all tetrapod vertebrates (Marín et al., 1998). In the standard pigeon brain atlas (Karten and Hodos, 1967) it is located below the ventral edge of the lateral forebrain ventricles in the septal area. According to some later studies, the avian Acc extends more posteriorly, ventrally, and laterally than shown in the atlas, surrounding the bed nucleus of the stria terminalis (Nst) (Mezey and Csillag, 2002; Roberts et al., 2002; Veenman et al., 1995). An analogous association with the Nst is considered characteristic of the caudal Acc of mammals (Chronister et al., 1980). The so-defined Acc area of birds receives an input from the ventral mesencephalic tegmentum (Durstewitz et al., 1998; Mezey and Csillag, 
2002). As it does in mammals, this reward signaling pathway appears to also rely on dopaminergic transmission in pigeons (Delius and Pellander, 1982). A glutamatergic innervation of the avian Acc has not yet been sought for, but it is known that it receives corticostriatal-like projections (Veenman et al., 1995). Glutamate receptors (GluR), however, have been detected elsewhere in the avian brain, including in their basal ganglia (Jiao et al., 2000; Reiner, 2002). It is proper to mention that a recent revision has relocated the avian Acc to a more anterior area than even that delineated in the atlas (Karten and Hodos, 1967) and has assigned the peri-Nst area to the ventral pallium (Reiner et al., 2004) without offering particularly cogent reasons for this. For continuity's sake we retain here the earlier Acc denomination for the caudal area.

In previous studies we found that the administration of $N$-methyl-D-aspartate ionotropic GluR (NMDA iGluR) antagonists into Acc disrupted a previously learned visual discrimination task (Acerbo et al., 2002; Gargiulo et al., 1998; Gargiulo, 2003). The treatments were assumed to have degraded or distorted the perceptual information essential for a proficient discrimination performance. Pigeons-far more so than rats-are highly visual organisms, much like humans are. The visuo-cognitive capacities of pigeons are gauged to be on par with those of smaller primate species (Delius and Delius, in press; Delius et al., 2001). Performance deficits in visual discrimination upon disturbances in cortico-associative areas of pigeons indicate that cognitive processes influence their visual perceptions (Aldavert-Vera et al., 1999; Delius et al., 1984).

The circumstance that experimental alterations of Acc transmission mechanisms affected the visual discriminative performance of pigeons in a schizophrenia-congruent manner (Acerbo et al., 2002; Gargiulo, 2003; Gargiulo et al., 1998; Gargiulo and Landa de Gargiulo, 2004) has suggested to us that the preparation could serve as a model to study the processes that might underlie the perceptuocognitive disturbances typical of schizophrenia (Conrad, 1966; Del Vecchio and Gargiulo, 1992; Silverstein et al., 2000). The purpose of the present study is to explore the potentialities of the pigeon preparation further by examining the effect of various glutamatergic and dopaminergic antagonists relevant in the context of that concept.

\section{Method}

\subsection{Subjects and apparatus}

Adult domestic pigeons (Columba livia) of local homing stock and weighing between 450 and $550 \mathrm{~g}$ were used. They were kept in individual $40 \times 45 \times 35 \mathrm{~cm}$ stainless steel grid cages located in a well-ventilated and illuminated (12 h on/12 h off) room and were maintained at $80 \%$ of their free feeding weight throughout the experiment. Because of logistic constraints the birds were randomly divided into two successively treated batches of initially 22 and 15 pigeons each. All the experimental treatments described in this paper complied with German animal welfare laws and regulations.

Horizontal conditioning platforms controlled by a personal computer were used (Xia et al., 1996). These were attached to the pigeons' home cages replacing their standard feeding troughs. Each platform incorporated two side-byside transparent pecking keys (diameter $2.5 \mathrm{~cm}$, centers 5 $\mathrm{cm}$ apart). Two light-emitting-diode matrices $(5 \times 7$ green diodes, $12 \times 17 \mathrm{~mm}$ ) served to present visual pattern stimuli under these keys. Two solenoid feeders could separately deliver rewards consisting of 3 to 6 millet seeds onto the two keys.

\subsection{Training procedure}

The pigeons were first shaped to peck the keys. This was done in successive blocks of 40 trials. Each trial began with a 20-s inter-trial interval. A small pentagonal stimulus was then presented for $8 \mathrm{~s}$ randomly under either the right or the left key, the other key remaining unlit. A peck to the illuminated key delivered an immediate reward onto this key. The key remained lit for another $2 \mathrm{~s}$ while the pigeon fed and before the next inter-trial interval began. If the pigeon did not peck, a reward followed by the 2 -s feeding period was automatically issued at the end of the standard 8$\mathrm{s}$ stimulus presentation. As soon as $80 \%$ of the trials of a block yielded pecks, these latter free rewards were discontinued; the pigeons being only rewarded if they pecked the key during a now continuous presentation of the stimulus. When the subjects had emitted 40 such instrumental responses, they entered the training phase.

The daily training sessions consisted of 10 blocks of 40 trials each. A trial began with the simultaneous presentation of two discriminative stimuli under the keys. Two mirrorimage visual stimuli were used, a p-like shape and a q-like shape (size: $3 \times 5$ diodes, $7 \times 12 \mathrm{~mm}$ ) in either a standard or an inverted $\left(180^{\circ}\right.$ rotated) orientation. The two types of stimulus pairs and the right/left key allocation of the relevant stimuli were randomized across the successive trials of each block. The $\mathrm{p}$ (or d) shape was defined as correct, the $\mathrm{q}$ (or b) shape as incorrect. The stimuli remained lit until the pigeons delivered altogether three pecks to either one or the other key. When this response requirement was completed on the key showing a correct stimulus it yielded a reward followed by a 2 -s feeding time with the stimuli still being lit. When the response requirement was completed on the key displaying the incorrect stimulus it yielded a penalty consisting of a 2-s time-out with the whole stimulus matrix lit. In either case, a 2 -s inter-trial interval with dark stimulus matrices always preceded the next trial. Trials ending in penalty were followed by a repeat trial with exactly the same stimulus configuration. This correction procedure ended when the pigeon chose the correct stimulus. The number of correct and of repeat trials was separately recorded. The correct-trial counts naturally excluded the terminal correcting trials. The 
training phase ended when a criterion of $80 \%$ correct trials was achieved within a block of trials.

\subsection{Surgery and testing}

The pigeons were then chronically cannulated. Anesthesia was induced by a combined xylazine and ketamine i.m. dose and maintained with additional doses of ketamine (Gargiulo et al., 1998). With a stereotaxic apparatus, each pigeon was implanted with two stainless steel guide cannulas (23 gauge, $13 \mathrm{~mm}$ long) with their beveled tips aimed towards but kept $2 \mathrm{~mm}$ short (see below) of the right and left Acc at the stereotactic coordinates A 8.5, L 2.0, D 7.5 of the pigeon brain atlas (Karten and Hodos, 1967). The cannulas were fixed to the skull with acrylic cement and were closed with removable stainless steel pins (30 gauge, $13 \mathrm{~mm}$ long). After surgery, the pigeons were allowed a week to recover. They were then retrained until they reattained the $80 \%$ correct criterion before testing began.

A test with a given drug involved two sessions carried out on two consecutive days. Immediately before the first of these sessions the pigeons were injected bilaterally with $1 \mu \mathrm{l}$ saline doses and immediately before the second session they were injected bilaterally with $1 \mu \mathrm{l}$ drug solution doses (see below). The occlusion pin of the relevant cannula was removed and a 30-gauge stainless steel injection cannula connected to a microsyringe was inserted through the guide cannula. The length of the injection cannula $(15 \mathrm{~mm})$ was adjusted to reach the Acc at the above-listed stereotactic coordinates. The volumes were gradually injected over 2 min periods and the injection cannula was left in place for an additional $1 \mathrm{~min}$ to allow diffusion. Immediately afterwards they were returned to their cage where the test sessions proceeded as described before, but consisted now of 3 blocks of 40 reinforced trials each. The pigeons took about $20 \mathrm{~min}$ to complete them. The data recorded for each bird and session were the number of correct trials and the number of repeat trials after incorrect trials. Between the successive pairs of sessions pertaining to the different drugs there was an interval of at least 1 day. The different drugs were administered according to the sequential scheme detailed below. The interposed saline sessions allowed to check whether a return to baseline performance had occurred before the administration of the next drug. Correct trials and repeat trials scores for each pigeon in each of the saline and drug sessions were tabulated. Means and standard errors for saline sessions and drug sessions were calculated. The data sets were checked for normality with Kolmogorov-Smirnov tests and then subjected to parametric analyses of variance (ANOVAs) and paired Student's $t$-tests.

\subsection{Drugs and histology}

The drug doses and the order in which they were administered over the drug sessions were as follows. First batch of pigeons: (1) the D1 dopaminergic receptor antagonist SCH-23390 (R-(+)-7-chloro-8-hydroxy-3methyl-1-phenyl-2,3,4,5-tetrahydro-1H-3-benza-zepine, Tocris), $1 \mu \mathrm{g} / \mu \mathrm{l}$; (2) the D2 dopaminergic receptor antagonist Spiperone (8(4-(4-fluorophenyl)-4-oxobutyl)-1-phenyl-1,3,8,triazaspiro-(4,5)decan-4-one, Tocris), $1 \mu \mathrm{g} / \mu 1$; (3) the NMDA iGluR allosteric glycine site antagonist Cycloleucine (1-aminocyclo-pentanecarboxilic acid, Sigma), $3 \mu \mathrm{g} / \mu \mathrm{l}$ ); and (4) the selective NMDA iGlu antagonist CGS 19755 (cis-4-(phosphonomethyl)-piperidine-2-carboxilic acid, Sigma), $0.01 \mu \mathrm{g} / \mu \mathrm{l}$. Second batch of pigeons: (1) the non-NMDA iGlu antagonist CNQX (6cyano-7-nitroquinoxaline-2,3-dione disodium, Tocris), $2.5 \mu \mathrm{g} / \mu \mathrm{l} ;(2)$ the selective II/III mGluR antagonist CPPG ( $R S$-alpha-cyclopropyl-4-phospho-nophenylglycine, Tocris), $1 \mu \mathrm{g} / \mu \mathrm{l}$; and (3) the selective III/II mGluR antagonist MPPG (RS-alpha-methyl-4-phosphonophenylglycine, Tocris), $1 \mu \mathrm{g} / \mu \mathrm{l}$. All the drugs were dissolved in saline and injected as detailed above. The doses employed were chosen on the basis of both published information and own preliminary results.

After the pigeons had completed the above treatments they were anaesthetized, i.c. injected with $1 \mu \mathrm{l}$ cresyl violet solution into each brain side and then perfused transcardially with saline and $4 \%$ formaline in phosphate saline buffer solution. The brains were removed from the skull and postfixed in the same formaline solution. After bathing in a $30 \%$ saccharose solution for a few days the brains were blocked and sectioned $(40 \mu \mathrm{m})$ with a cryotome. The tissue block face was continuously inspected with a $10 \times$ magnifying lens and every 5th section around the injection sites was mounted. The injection sites were located with the aid of a microscope and transferred to standard brain section.

\section{Results}

\subsection{Histology}

Of the 18 pigeons in the first batch that were successfully trained, cannulated and tested, 11 had their injection sites (small lesions, stain deposit) bilaterally located within the Acc or its immediate neighbourhood whereas in 7 pigeons at least one of the injection sites lay well away from the Acc or within the overlying lateral ventricle (Fig. 1, left). Of the 13 pigeons of the second batch that were successfully trained, cannulated and tested, 12 had their injection sites similarly located in the Acc or its immediate neighbourhood whereas in one pigeon the injection sites lay well outside the Acc (Fig. 1, right).

\subsection{Training and testing}

The 18 pigeons of the first batch needed between 19 and 70 (median 28) blocks of discrimination training to reach the $80 \%$ correct discrimination criterion. After surgery they 


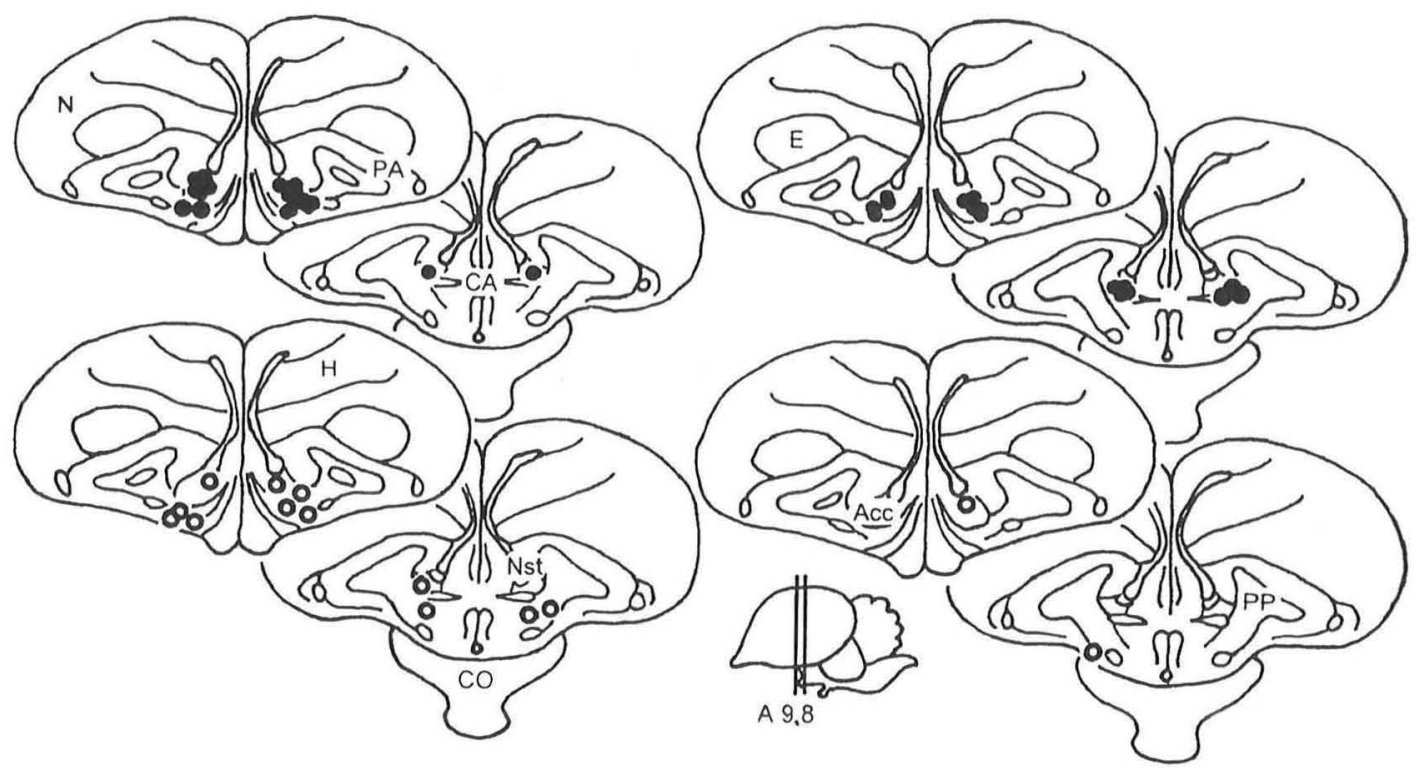

Fig. 1. Frontal brain sections showing the location of the injection sites. Filled circles mark the injection sites where both right and left sites were within the Acc or its immediate neighborhood. Open circles mark the injection sites of pigeons with at least one site outside the Acc (ventricle or otherwise). Left: 11 plus 7 pigeons of first batch. Right: 12 plus 1 pigeons of second batch. Abbreviations: Acc, nucleus accumbens; CA, comissura anterior; CO, chiasma opticum; E, ectostriatum; H, hyperstriatum; Nst, nucleus stria terminalis; N, neostriatum; PA, paleostriatum augmentatum; PP, paleostriatum primitivum; S, septum. A8 and A9 refer to stereotaxic planes (Karten and Hodos, 1967).

required between 6 and 47 (median 8) blocks to re-attain the same criterion. The 13 pigeons of the second batch needed between 7 and 55 (median 27) blocks of discrimination training to reach the $80 \%$ criterion. After surgery they required between 2 and 31 (median 5) blocks to re-attain that criterion.

The 11 pigeons of the first batch that received bilateral injections into the Acc or its immediate neighborhood exhibited a steady baseline performance across the 4 saline sessions yielding an average $72.5 \pm 1.3 \%$ correct trials and an average $16.7 \pm 1.6$ repeat trials. Separate ANOVAs based on the individual data showed that the across-sessions variations of both measures were not significant (both $p$ 's $>0.05$ ). Sharply contrasting with that, separate ANOVAs showed that the variations of both correct trials and repeat trials scores across the 4 drug treatment sessions were significant $(p<0.01$ and $p<0.001)$. Regarding the 7 pigeons with misplaced injection sites, neither the saline baseline scores nor the drug treatment scores exhibited any significant across-sessions variations (ANOVAs, all $p$ 's $>0.05$ ). Tables 1 and 2 list the detailed drug by drug results. For clarity, the different baseline session averages were set here to equal $100 \%$, and in turn, the different drug treatment scores were expressed in percentages of the individually corresponding saline baseline scores.

Paired $t$-tests comparisons between saline and drug session indicated that Spiperone, a D2-dopamine and 5HT2a-serotonine antagonist, improved the performance by significantly $(p<0.05)$ decreasing the number of repeat trials. Inversely, CGS 19755, a competitive NMDA iGluR antagonist, caused a significant decrease in the number of correct trials $(p<0.01)$ and an increase in the number of repeat trials $(p<0.001)$ against the corresponding baselines. Neither a motivational nor any motor impairment seemed to be involved since the pigeons began to key-peck immediately, completed the corresponding sessions about as swiftly as the baseline sessions and directed their pecks accurately at the keys. Neither SCH-23390, a potent D1 dopamine antagonist, nor Cycloleucine, an allosteric glycine site antagonist of the NMDA iGluR, had a significant effect. None of the drugs, including CGS 19755, had any significant effect when injected outside the Acc area in at least one of the two brain halves (Table 2).

The 11 pigeons of the second batch that received bilateral injections into the Acc or its immediate neighborhood exhibited a steady baseline performance across the 3 saline

Table 1

First batch pigeons $(n=11)$ injected bilaterally into the Acc or its immediate neighbourhood with Saline (baselines), SCH-23390, Spiperone, Cycloleucine and CGS-19755

\begin{tabular}{|c|c|c|c|c|c|c|c|c|}
\hline & Saline & SCH-23390 & Saline & Spiperone & Saline & Cycloleucine & Saline & CGS-19755 \\
\hline Correct & $100.0 \pm 3.1$ & $104.1 \pm 1.0$ & $100.0 \pm 2.9$ & $103.7 \pm 2.9$ & $100.0 \pm 2.5$ & $103.0 \pm 2.9$ & $100.0 \pm 2.3$ & $84.3 \pm 2.8^{* *}$ \\
\hline Repeat & $100.0 \pm 11.3$ & $88.5 \pm 7.3$ & $100.0 \pm 7.5$ & $82.2 \pm 7.2^{* *}$ & $100.0 \pm 10.3$ & $82.7 \pm 7.9$ & $100.0 \pm 9.8$ & $181.3 \pm 11.9^{* * *}$ \\
\hline
\end{tabular}

Across pigeons mean percent ( \pm S.E.) correct trials and repeat trials for baseline and treatment sessions. Asterisks denote significant saline-drug differences. 
Table 2

First batch pigeons $(n=7)$ injected outside the Acc in at least one brain side with Saline (baselines), SCH-23390, Spiperone, Cycloleucine and CGS-19755

\begin{tabular}{|c|c|c|c|c|c|c|c|c|}
\hline & Saline & SCH-23390 & Saline & Spiperone & Saline & Cycloleucine & Saline & CGS-19755 \\
\hline Correct & $100.0 \pm 2.9$ & $105.7 \pm 5.2$ & $100.0 \pm 5.0$ & $101.6 \pm 5.1$ & $100.0 \pm 3.8$ & $99.7 \pm 4.8$ & $100.0 \pm 3.3$ & $103.9 \pm 5.6$ \\
\hline Repeat & $100.0 \pm 9.1$ & $92.7 \pm 14.9$ & $100.0 \pm 10.8$ & $88.4 \pm 10.5$ & $100.0 \pm 8.1$ & $96.1 \pm 9.9$ & $100.0 \pm 9.6$ & $89.7 \pm 14.2$ \\
\hline
\end{tabular}

Across pigeons mean percent $( \pm$ S.E.) correct trials and repeat trials for saline baseline and drug treatment sessions. There are no significant saline-drug differences.

sessions yielding an average $72.9 \pm 1.7 \%$ correct trials and an average $18.9 \pm 2.2$ repeat trials. Separate ANOVAS showed that the variations of both the correct trial and repeat trial scores across the saline baseline sessions were not significant (both $p$ 's $>0.05$ ). Contrasting with that, separate ANOVAS showed that the variations of both the percent correct and repeat trials scores across the drug treatment sessions were significant (both $p$ 's $<0.05$ ). For clarity, as before, the detailed saline and drug results shown in Table 3 are again expressed in terms of percentages.

Paired $t$-tests showed that CNQX, a potent non-NMDA iGluR antagonist, had not yielded any significant effect. However, CPPG, a potent group II and III metabotropic glutamate receptor (II/III $\mathrm{mGluR}$ ) antagonist, caused the correct trials to increase $(p<0.01)$ and the repeat trials to decrease $(p<0.01)$. In the single pigeon with an injection site outside the Acc CPPG had, if anything, a depressing effect on performance. MMPG, a potent group III and weaker group II mGluR antagonist, yielded no significant differences.

\section{Discussion}

\subsection{Dopamine receptor antagonists}

The dopaminergic Acc blockades had mixed effects on the pigeons' visual discrimination performance. At the dose employed the D1-type receptor blocker SCH-23390 had no effect. The D2-type receptor blocker Spiperone, however, decreased the incidence of repeat trials, this constituting a performance improvement. Previously we had found that apomorphine, an unspecific D1- and D2-type receptor agonist, had no effect on the performance of the same discrimination task (Gargiulo et al., 1998). The same dose of apomorphine administered intracerebrally in several other brain locations than the Acc was effective in eliciting pecking, the relevant motor response in the present task (Acerbo et al., 2002). Moreover, this apomorphine-induced pecking which can also be elicited with systemically injected apomorphine is associated with a discriminatory learning process (Acerbo et al., 2003; Keller and Delius, 2001). However, both these effects appear to have more to do with the acquisition than with the retrieval of a behavioral response (Acerbo and Delius, 2004; Acerbo et al., 2004; Schultz, 2002).

\subsection{NMDA ionotropic glutamate receptor antagonists}

The competitive NMDA iGluR blockers AP-5 and AP-7 were previously both found to impair the performance of the same visual discrimination used here (Acerbo et al., 2002; Gargiulo et al., 1998). An analogous impairment was obtained here with the competitive NMDA iGluR antagonist CGS-19755. Although the relevant receptors are considered to be mainly involved in the acquisition and consolidation of learned tasks (Jerusalinsky et al., 1992; Martinez et al., 2002a), there is nevertheless evidence that they also participate in the retrieval of previously memorized information (Acerbo et al., 2004; Maldonado-Irizarry and Kelley, 1995).

Cycloleucine, a non-competitive NMDA iGluR antagonist (Scatton, 1993), acting on a modulatory glycine site (Millan, 2002), yielded no effects (see also Acerbo et al., 2002). The selective NMDA iGluR competitive blockers CGS-19755 had a performance depressing effect much as NMDA iGluR competitive blockers AP-5 and AP-7 had in the previous studies (Acerbo et al., 2002; Gargiulo et al., 1998). Whatever the precise role of these antagonists is, it seems now certain that NMDA iGluR are present in the pigeon's Acc and that they are somehow involved in the retrieval of a learned discriminative performance.

\subsection{Non-NMDA ionotropic glutamate receptor antagonists}

Our evidence suggests that non-NMDA iGluRs are not implicated in the pigeon's discriminatory performance. But our results disagree with findings relating to these receptors in the hippocampus of rats where they were found to be involved in the retrieval of learned tasks (Izquierdo et al.,

Table 3

Second batch pigeons $(n=11)$ injected bilaterally into the Acc or its immediate neighborhood with Saline (baselines), CNQX, CPPG and MPPG

\begin{tabular}{lllllll}
\hline & Saline & CNQX & Saline & CPPG & Saline \\
\hline Correct & $100.0 \pm 3.0$ & $100.5 \pm 3.6$ & $100.0 \pm 3.2$ & $106.8 \pm 3.9 * *$ & $100.0 \pm 4.0$ & $102.9 \pm 4.4$ \\
Repeat & $100.0 \pm 21.2$ & $73.0 \pm 9.3$ & $100.0 \pm 13.0$ & $81.6 \pm 11.1 * *$ & $100.0 \pm 14.5$ & $97.2 \pm 18.0$ \\
\hline
\end{tabular}

Across pigeons mean percent ( \pm S.E.) correct trials and repeat trials for saline baseline and for drug treatment sessions. Asterisks denote significant saline-drug differences. 
2000; Riedel et al., 1999). It is possible that the non-NMDA iGluR of pigeons have a lesser affinity to CNQX (and also to NBQX: see Gargiulo et al., 1998) than those of rats and that the doses used here were too low to produce behaviorally detectable effects. The low hydrosolubility of CNQX unfortunately limits the drug amount that can be intracerebrally administered.

\subsection{Metabotropic glutamate receptor antagonists}

The doubtlessly most striking result of the present study is that the II/III mGluR blocker CPPG, but not the III/II mGluR blocker MMPG, enhanced the pigeon's performance on the shape discrimination task. It is not often found that the intracranial administration of a drug results in a better than baseline performance of a learned task. The type II mGluRs that seem to be mainly implicated are known to be presynaptically located and to have an inhibitory action on the glutamate release (Kilbride et al., 1998). It is therefore probable that an augmented postsynaptic glutamate release was responsible for the discrimination improvement obtained. Our previous findings have shown that a blockade of glutamatergic transmission in the pigeon's Acc impaired the discrimination performance (Acerbo et al., 2002; Gargiulo et al., 1998). But it is also possible that the II mGluR blockage down-regulated the release of dopamine from the corresponding terminals (Verma and Moghaddam, 1998) and restored the balance between NMDA and nonNMDA iGluR activations, since type II mGluR agonists have a presynaptic inhibitory effect (Javitt and Coyle, 2004; Kilbride et al., 1998).

\section{Conclusion}

Earlier we suggested that glutamatergic blockades of the Acc lead to behavioral modifications that in pigeons may be considered as modeling the positive (perceptual disfunction) symptoms (Acerbo et al., 2002; Gargiulo et al., 1998) and that in rats can be thought as modeling the negative (affective flattening) symptoms of schizophrenia (Gargiulo, 2003; Martinez et al., 2002b). Recent clinical studies support the view that both these symptoms have a common pathophysiology (Heydebrand et al., 2004). The prevalent view is that they are caused by a glutamatergic hypofunction which only secondarily causes a dopaminergic hyperfunction (Carlsson et al., 2000; Laruelle et al., 1996). This dysfunction probably affects projections converging onto the Acc and thus the glutamatergic cortical afferents to the Acc are thought to be crucial (Grace, 2000).

Schizophrenics exhibit a decreased activity within the prefrontal cortex (Friston, 1992; Liddle et al., 1992a,b). In mammals the prefrontal cortex is known to send glutamatergic projections to the Acc (O'Donnel and Grace, 1993; Sesack et al., 1989) that are in turn inhibited by presynaptic D2 dopaminergic inputs (O'Donnel and Grace, 1994). In pigeons lesions of an area presumed to be an equivalent of the mammalian prefrontal cortex were found to impair the performance of the same visual discrimination task used in the present study (Aldavert-Vera et al., 1999; but see Reiner et al., 2004). Our results concerning the improved discrimination performance observed after intra-Acc Spiperone administration might be attributable to a blocking of the dopaminergic inhibition. Conversely an inhibition of the presynaptic II mGluR autoreceptores of the glutamatergic cortico-accumbens pathway could explain the performance improvement we observed after intra-Acc injections of CCPG.

We assume that blockages of the glutamatergic inputs that impinge on the Acc interfere with the perception of the visual cues that normally serve to guide the pigeons towards the goal rewards. Within this framework NMDA iGluR antagonist (AP-5, AP-7, CGS-19755) injections into the Acc lead postsynaptically to a decreased glutamatergic transmission which impairs the discrimination, while the autoreceptor blocking by II/III mGluR antagonists lead to a presynaptic enhancement of glutamate release and an improvement of discrimination performance. The effect obtained with Spiperone might have arisen in a similar way as D2 receptor blockades of Acc interfere with the dopaminergic inhibition of glutamatergic terminals. These effects were primarily judged in terms of percent correct choices. The alterations in repeat trial scores may reflect the same processes but could also have to do with the induction of response perseveration. This persistence may relate to stereotyped behavior and cognitive rigidity symptoms (Acerbo et al., 2002; Gargiulo et al., 1998; Gargiulo, 2003; Robbins, 1991). It is in any case noteworthy that in the pigeon model only the selective and competitive NMDA iGluR antagonists and the II mGluR antagonists affected both the discrimination performance measures.

\section{Acknowledgements}

The research was supported by a cooperation grant of the Volkswagen Stiftung, Hannover, to P.A. Gargiulo and J.D. Delius, and by grants of the Deutsche Forschungsgemeinschaft, Bonn, to J.D. Delius. It was carried out while P.A. Gargiulo was a visiting fellow in Konstanz. We thank Jennifer Lee for improving the English text.

\section{References}

Acerbo MJ, Delius JD. Behavioral sensitization to apomorphine in pigeons (Columba livia): blockade by the D1 dopamine antagonist SCH-23390. Behav Neurosci 2004;118:1080-8.

Acerbo MJ, Gargiulo PA, Krug I, Delius JD. Behavioural consequences of nucleus accumbens dopaminergic stimulation and glutamatergic blocking in pigeons. Behav Brain Res 2002;136:171-7.

Acerbo MJ, Godoy AM, Delius JD. Haloperidol blocks the acquisition, but not the retrieval of a conditioned response induced by apomorphine. Behav Pharmacol 2003;14:631-40. 
Acerbo MJ, Lee JM, Delius JD. Sensitization to apomorphine, effects of dizocilpine NMDA receptor blockades. Behav Brain Res 2004;151: $201-8$.

Aldavert-Vera L, Costa-Miserachs D, Divac I, Delius JD. Presumed "prefrontal cortex" lesions in pigeons: effects on visual discrimination performance. Behav Brain Res 1999;102:165-70.

Aultman JM, Moghaddam B. Distinct contributions of glutamate and dopamine receptors to temporal aspects of rodent working memory using a clinical relevant task. Psychopharmacology 2001;153:353-64

Baldo BA, Sadeghian K, Basso AM, Kelley AE. Effects of selective dopamine D1 or D2 subregions on ingestive behavior and associated motor activity. Behav Brain Res 2002;137:165-77.

Baldwin AE, Sadeghian K, Holahan MR, Kelley AE. Appetitive instrumental learning is impaired by inhibition of CAMP-dependent protein kinase within the nucleus accumbens. Neurobiol Learn Mem 2002; $77: 44-62$

Carlsson A, Waters N, Waters S, Carlsson ML. Network interactions in schizophrenia, therapeutic implications. Brain Res Rev 2000;31:342-9

Chronister RB, Sikes RW, Trow TW, De France JF. The organization of nucleus accumbens. In: Chronister RB, De France JF, editors. The Neurobiology of the Nucleus Accumbens Proceedings of a Nucleus Accumbens Symposium 1980. Maine: Haer Institute; 1981. p. $97-146$.

Conrad K. Die beginnende Schizophrenie Versuch einer Gestaltanalysis des Wahnsinns [Incipient schizophrenia: an attempt at a gestaltic analysis of insanity]. Stuttgart: Thieme; 1966.

Delius JD, Delius JA. Intelligences and brains, a comparative and evolutionary birdseye view. In: Wasserman EA, Zentall TR, editors Comparative cognition: experimental explorations of animal intelligence. London, Oxford University Press; in press.

Delius JD, Pellander K. Hunger dependence of electrical brain selfstimulation in the pigeon. Physiol Behav 1982;28:63-6.

Delius JD, Jäger R, Friesel M. Lateral telencephalic lesions affect visual discrimination in pigeons. Behav Brain Res 1984;11:249-58.

Delius JD, Siemann M, Emmerton J, Xia L. Cognitions of birds as products of evolved brains. In: Roth G, Wulliman MF, editors. Brain evolution and cognition. Wiley: New York; 2001. p. 451-90.

Del Vecchio S, Gargiulo PA. Visual and motor function in schizophrenic patients. Acta Psiquiátr Psicol Am Lat 1992;38:317-22.

Di Ciano P, Cardinal RN, Cowell RA, Little SJ, Everitt BJ. Differential involvement of NMDA, AMPA/kainate, and dopamine receptors in the nucleus accumbens core in the acquisition and performance of Pavlovian approach behavior. J Neurosci 2001;21:9471-7.

Durstewitz D, Kröner S, Hemmings HC, Güntürkün O. The dopaminergic inervation of the pigeon telencephalon: distribution of the DARP-32 and co-occurrence with glutamate decarboxylase and tyrosine hydroxylase. Neuroscience 1998;83:763-79

Friston KJ. The dorsolateral prefrontal cortex, schizophrenia and PET J Neural Transm 1992;37:79-93.

Gargiulo PA. Thyrotropin releasing hormone injected into the nucleus accumbens septi selectively increases face grooming in rats. Braz J Med Biol Res 1996;29:805-10.

Gargiulo PA. Aproximaciones experimentales a la disfunción perceptual en la esquizofrenia (Experimental approaches to perceptual dysfunction in schizophrenia). Rev Neurol 2003;37:545-51.

Gargiulo PA, Landa de Gargiulo AI. Perception and psychoses: the role of glutamatergic transmission within the nucleus accumbens septi. Behay Brain Sci 2004;27:792-3.

Gargiulo PA, Siemann M, Delius JD. Visual discrimination in pigeons impaired by glutamatergic blockade of nucleus accumbens. Physiol Behav 1998;63:705-9.

Gargiulo PA, Martínez G, Ropero C, Funes A, Landa AI. NMDA glutamatergic blockade of nucleus accumbens disrupts acquisition but not consolidation in a passive avoidance task. Ann N Y Acad Sci 1999;877:717-22.

Grace AA. Gating of information flow within the limbic system and the pathophysiology of schizophrenia. Brain Res Rev 2000;31:330-41.
Gray JA. Dopamine release in the nucleus accumbens: the perspective from aberrations of consciousness in schizophrenia. Neuropsychology 1995;33:1143-53.

Heimer L. Basal forebrain in the context of schizophrenia. Brain Res Rev 2000;31:205-35.

Heydebrand G, Weiser M, Rabinowitz J, Hoff AL, DeLisi LE, Csernansky JC. Correlates of cognitive deficits in first episode schizophrenia. Schizophr Res 2004;68:1-9.

Izquierdo LA, Barros DM, Ardenghi PG, Pereira P, Rodriguez C, Choi H, et al. Different hippocampal molecular requirements for short- and long-term retrieval of one-trial avoidance learning. Behav Brain Res 2000;111:93-8.

Javitt DC, Coyle JT. Decoding schizophrenia A fuller understanding of signaling in the brain of people with this disorder offers new hope for improved therapy. Sci Am 2004;290:38-45.

Jerusalinsky D, Ferreira MB, Walz R, Da Silva RC, Bianchin M, Ruschel $\mathrm{AC}$, et al. Amnesia by post-training infusion of glutamate receptor antagonists into the amygdala, hippocampus and enthorinal cortex. Behav Neural Biol 1992;58:76-80.

Jiao Y, Medina L, Veenman CL, Toledo C, Puelles L, Reiner A. Identification of the anterior nucleus of the ansa lenticularis in birds as the homolog of the mammalian subthalamic nucleus. J Neurosci 2000;20:6998-7010.

Karten HJ, Hodos WA. Stereotaxic atlas of the brain of the pigeon. Baltimore: Johns Hopkins Press; 1967.

Keller S, Delius JD. Discriminative learning occasioned by the administration of a dopamine antagonist. Psychopharmacology 2001;157: $320-3$.

Kelley AE, Berridge KC. The neuroscience of natural rewards: relevance to addictive drugs. J Neurosci 2002;22:3306-11.

Kilbride J, Huang LQ, Rowan MJ, Anwyl R. Presynaptic inhibitory action of the group II metabotropic glutamate receptor agonists, LY354740 and DCG-IV. Eur J Pharmacol 1998;356:149-57.

Laruelle M, Abi-Dargham A, van Dyck CH, Gil R, D’Souza CD, Erdos J, et al. Single photon emission computerized tomography imaging of amphetamine-induced dopamine release in drug-free schizophrenic subjects. Proc Natl Acad Sci 1996;93:9235-40.

Liddle PF, Friston KJ, Frith $\mathrm{CD}$, Frachowlak RSJ. Cerebral blood flow and mental processes in schizophrenia. J R Soc Med 1992a $85: 224-7$.

Liddle PF, Friston KJ, Frith CD, Hirsch SR, Jones T, Frachowlak RSJ Patterns of cerebral blood flow in schizophrenia. Br J Psychiatry $1992 b ; 160: 179-86$.

Maldonado-Irizarry CS, Kelley AE. Excitatory amino acid receptors within nucleus accumbens subregions differentially mediate spatial learning in the rat. Behav Pharmacol 1995;6:527-39.

Marín O, Smeets WJ, Gonzales A. Basal ganglia in tetrapods. Trends Neurosci 1998;21:487-94.

Martinez GW, Ropero C, Funes A, Flores E, Landa AI, Gargiulo PA. AP 7 into the nucleus accumbens disrupts acquisition but does not affect consolidation in a passive avoidance task. Physiol Bchav 2002a;76 $205-12$.

Martinez GW, Ropero C, Funes A, Flores E, Blotta C, Landa AI, et al Effects of NMDA and non-NMDA blockade in the nucleus accumbens on the plus maze test. Physiol Behav 2002b;76:219-24.

Mezey S, Csillag A. Selective striatal connections of midbrain dopaminergic nuclei in the chick (Gallus domesticus). Cell Tissue Res 2002; 308:35-46.

Millan MJ. N-methyl-D-aspartate receptor-coupled glycine B receptors in the pathogenesis and treatment of schizophrenia: a critical review. Curr Drug Target CNS Neurol Disord 2002;1:191-213.

O'Donnel P, Grace AA. Physiological and morphological properties of accumbens core and shell neurons recorded in vitro. Synapse $1993 ; 13: 135-60$.

O'Donnel P, Grace AA. Tonic D2-mediated attenuation of cortical excitation in nucleus accumbens neurons recorded in vitro. Brain Res 1994;634:105-12 
Reiner A. Functional circuitry of the avian ganglia: implications for basal ganglia organization in stem amniotes. Brain Res Bull 2002;57: $513-28$

Reiner A, Perkel DJ, Bruce LL, Butler AB, Csillag A, Kuenzel W, et al. Avian Brain Nomenclature Forum Revised nomenclature for avian telencephalon and some related brainstem nuclei. J Comp Neurol 2004:473:377-414

Riedel G, Micheau J, Lam AG, Roloff E, Martin SJ, Bridge H, et al. Reversible neural inactivation reveals hippocampal participation in several memory processes. Nat Neurosci 1999;2:898-905.

Robbins TW. Cognitive deficits in schizophrenia and Parkinson's disease: neural basis and the role of dopamine. In: Willner P, Scheel-Kruger J, editors. The mesolimbic dopamine system: from motivation to action. New York: Wiley; 1991. p. 497-528.

Roberts TF, Hall WS, Brauth SE. Organization of the avian basal forebrain: chemical anatomy in the parrot (Melopsittacus undulatus). J Comp Neurol 2002;454:383-408.

Roullet P, Sargolini F, Oliverio A, Mele A. NMDA and AMPA antagonist infusions into the ventral striatum impair different steps of spatial information processing in a nonassociative task in mice. J Neurosci 2001;21:2143-9.

Scatton B. The NMDA receptor complex. Fundam Clin Pharmacol 1993;7:389-400.
Schultz W. Getting formal with dopamine and reward. Neuron 2002;36: $241-63$.

Sesack SR, Deutch AY, Roth RH, Bunney BS. Topographical organization of the efferent projections of the medial prefrontal cortex in the rat: an anterograde tract-tracing study with Phaseolus vulgaris leucoagglutinin. J Comp Neurol 1989;290:213-42.

Silverstein SM, Kovacs I, Corry RL, Valone C. Perceptual organization, the disorganization syndrome, and context processing in chronic schizophrenia. Schizophr Res 2000;43:11-20.

Smith-Roe SL, Kelley AE. Coincident activation of NMDA and dopamine D1 receptors within the nucleus accumbens core is required for appetitive instrumental learning. J Neurosci 2000;20:7737-42.

Veenman CL, Wild JL, Reiner A. Organization of the avian "corticostriatal" projection system, a retrograde and anterograde pathway tracing study in pigeons. J Comp Neurol 1995;354:87-126.

Verma A, Moghaddam B. Regulation of striatal dopamine release by metabotropic glutamate receptors. Synapse 1998;28:220-6.

Xia L, Delius JD, Siemann MA. Multistimulus, portable and programmable conditioning panel for pigeons. Behav Res Methods Instrum Comput $1996 ; 28: 49-54$ 